\title{
Does TLIF Aggravate Adjacent Segmental Degeneration More Adversely than ALIF? A Finite Element Study
}

\author{
TLIF Komşu Segmental Dejenerasyonu ALIF'den Daba Olumsuz \\ Etkiler mi? Bir Sonlu Eleman Çalısması
}

\author{
Shujie TANG \\ Jinan University, Medical School, Department of Traditional Chinese Medicine, Guangzhou, China
}

Correspondence address: Shujie TANG / E-mail: wkdd2009@hotmail.com

\begin{abstract}
AIM:To determine whether transforaminal lumbar interbody fusion aggravate adjacent segmental degeneration more adversely than anterior lumbar interbody fusion.

MATERIAL and METHODS: A normal finite element model, an anterior lumbar interbody fusion model and a transforaminal lumbar interbody fusion model of $\mathrm{L} 3-5$ were developed. $800 \mathrm{~N}$ compressive loading plus $10 \mathrm{Nm}$ moments simulating flexion, extension, lateral bending and axial rotation were imposed on L3 superior endplate. The intradiscal pressure, intersegmental rotation and tresca stress in L3-4 were investigated.

RESULTS: Under all loading directions, the values of three parameters in transforaminal lumbar interbody fusion model were the highest and those in normal model were the lowest, and the values in the ALIF model were higher than the normal model while lower than the TLIF model. In the ALIF and normal models, the values of the three parameters on left lateral bending and axial rotation were equal to those on right lateral bending and axial rotation. However, in the TILF model, the values on right lateral bending and axial rotation were larger than those on left lateral bending and axial rotation.
\end{abstract}

CONCLUSION: Transforaminal lumbar interbody fusion aggravates adjacent segmental degeneration more adversely than anterior lumbar interbody fusion.

KEYWORDS: Anterior lumbar interbody fusion (ALIF), Transforaminal lumbar interbody fusion (TLIF), Adjacent segmental degeneration (ASD)

öz

AMAÇ: Transforaminal lumber interbody füzyonun komşu segment dejenerasyonunu anterior lumber interbody füzyondan daha olumsuz etkileyip etkilemediğini belirlemek.

YÖNTEM ve GEREÇLER: Bir normal sonlu eleman modelini kullanarak L3-5 için bir anterior lumber interbody füzyon modeli ve bir transforaminal lumber interbody füzyon modeli geliştirildi. L3 superior uç plakasına fleksiyon, lateral bükülme ve aksiyal rotasyon simülasyonu yapan 10 $\mathrm{Nm}$ momentler artı $800 \mathrm{~N}$ kompresif yükleme uygulandı. Intradisk basıncı, intersegmental rotasyon ve tresca stresi L3-4'te incelendi.

BULGULAR: Tüm yükleme yönlerinde üç parametrenin değeri transforaminal lumbar interbody füzyon modelinde en yüksek olurken normal modelde en düşüktü ve ALIF modelindeki değerler normal modelden yüksekken TLIF modelinden düşüktü. ALIF ve normal modellerde üç parametrenin sol lateral bükülme ve aksiyal rotasyon değerleri sağ lateral bükülme ve aksiyal rotasyon için olanlara eşitti. Ancak, TLIF modelinde sağ lateral bükülme ve aksiyal rotasyon değerleri sol lateral bükülme ve aksiyal rotasyon için olandan daha büyüktü.

SONUÇ: Transforaminal lumber interbody füzyon komşu segmental dejenerasyonu anterior lumber interbody füzyondan daha olumsuz etkilemektedir.

ANAHTAR SÖZCÜKLER: Anterior lumber interbody fusion (ALIF), Transforaminal lumber interbody fusion (TLIF), Komşu segment dejenerasyonu (ASD)

\section{INTRODUCTION}

Transforaminal lumbar interbody fusion (TLIF) and anterior lumbar interbody fusion (ALIF) have similar indications, and both modalities have been a standard technique of lumbar interbody fusion used to treat degenerative disc disease, spondylolisthesis, spinal deformity, and pseudarthrosis. Many reports have been published about the surgical results of the two modalities, most of which suggested that the two techniques had no significant difference in terms of morbidity or mortality rates, blood loss, surgical time and functional outcomes $(5,6)$. However, no reports, comparing the influence of ALIF and TLIF on adjacent segmental degeneration have been published. 
In addition, inherent limitations in clinical research and conventional experiments make discrete characterization of the effects of lumbar interbody fusion on the adjacent segment significantly difficult. Specimens for cases and controls are difficult to obtain and standardize, and subsequent repetitive testing under various loads can result in significant sample variability (10). In contrast, the finite element modeling technique mitigates these problems. It is highly reproducible and repeatable. Adjustments can be made to the models to affect the material properties, simulate different situations of spine either in normal or fusion conditions, show stress distribution under different loading modes, or reflect any structural change. Compared with other experimental methods, the finite element method has many advantages, facilitating a comparative study among different models (10).

We therefore developed a three-dimensional finite element model of L3-5 for the normal, healthy spine, along with an ALIF model and a TLIF model, and our objectives were: 1) to compare the biomechanical effect of ALIF and TLIF on the adjacent segment; 2 ) to determine if TLIF aggravates adjacent segmental degeneration more adversely than ALIF.

\section{MATERIAL and METHODS}

A three-dimensional numerical model of a two-level ligamentous lumbar segment (3 vertebrae and 2 discs) was built and implemented with the finite element model (FEM) software ANSYS 10.0. Three different configurations of the model were considered: (1) a normal healthy model of L3-5 (Figure 1); (2) an ALIF model and (3) a TLIF model. The normal model was well validated in the past studies (9). The ALIF and TLIF models were modified from the normal model by changing the geometry or material properties of the L4-5 segment. We assume the elements of the L3-4 segments including intervertebral disc, facet joints, endplates, and vertebral bodies to be normal in all finite element models.

\section{Normal model}

A non-linear, three-dimensional FEM of L3-5 was created with geometry based on the high resolution computed tomography scan (slice thickness of $0.75 \mathrm{~mm}$ ) of a 26 -year-old healthy male volunteer. The FEM of the ligamentous lumbar spine consisted of vertebrae, intervertebral discs, endplates, superior and inferior facet articulating surfaces, ligaments and capsules. Spinal structures that could not be recognized using computer tomography were determined by magnetic resonance imaging and histological observations (8).

The modeled vertebrae and intervertebral discs were meshed using eight-node solid 186 elements. The vertebrae and intervertebral discs model consists of 156806 elements and the seven spinal ligaments were represented by 2-node link 10 elements, which do not offer resistance in compression. The surfaces of facet joints were simulated by a cartilaginous layer, which was assumed to be multi-linear elastic in compression. The contact between the facet joints was simulated by surface to surface contact elements without

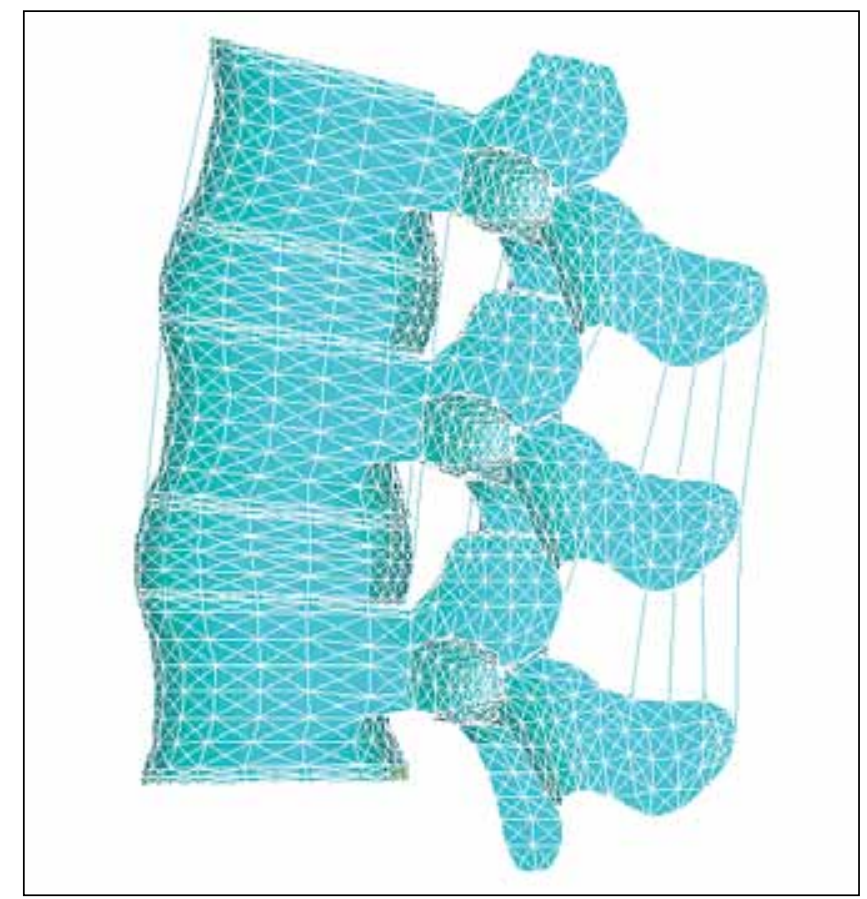

Figure 1: Normal finite element model of L3-5.

friction. The facet joints have a gap of $0.5 \mathrm{~mm}$ and can only transmit compressive forces.

The intervertebral discs consisted of the nucleus pulposus and the surrounding annulus fibrosus. The nucleus pulposus, modeled as an incompressible material, was $43 \%$ of the total disc volume and located slightly posterior to the center of the disc (12). The annulus fibrosus was assumed to be a composite of a homogenous ground substance reinforced by collagen fibers. Seven crisscross fiber layers were defined in the radial direction and the fibers were mounted in two times seven layers with orientation of $\pm 30^{\circ}$ to the midcross-sectional plane. The fiber content of the modeled annulus fibrosus was approximately 19\%, appropriate for the natural collagen content of the annulus. The material constants for the nucleus and annulus ground substance were defined according to previously accepted values (4) (Table I).

\section{The ALIF and TLIF models}

To mimic ALIF and TLIF, the L4-5 disc of the normal model was removed and replaced by the interbody bone graft, which was assumed to have the same dimensions as healthy disc and the same material properties as cancellous bone. In addition, bone grafts were placed between the transverse processes of L4-5 segment of the TLIF model bilaterally. To facilitate the study, all the grafts were assumed to have gained solid fusion and internal fixation instrumentations were removed. TLIF was assumed to be performed on the left so the total facetectomy was performed at the L4-5 segment and the left facet joint and ligamentum flavum were removed, and the left superior and inferior lamina were partially removed, but the posterior elements, contralateral facet joint, supraspinous ligaments, and interspinous ligaments were preserved. 
Table I: The Material Properties in the Finite Element Models

\begin{tabular}{|c|c|c|c|c|}
\hline Material & Young's modulus (Mp $)$ & Poisson's ratio & Element number & Cross-section $\left(\mathrm{mm}^{2}\right)$ \\
\hline Cortical bone & 12000 & 0.3 & & \\
\hline Cancellous bone & 100 & 0.2 & & \\
\hline Posterior elements & 3500 & 0.30 & & \\
\hline Nucleus pulposus & 1 & 0.499 & & \\
\hline Annulus ground substance & 4.2 & 0.45 & & \\
\hline Fiber & 92 & 0.45 & & \\
\hline Endplate & 500 & 0.25 & & \\
\hline Facet cartilage & 3500 & 0.25 & & \\
\hline Capsular ligament & 7.7 & 0.39 & 24 & 102.5 \\
\hline Anterior longitudinal ligament & 11.9 & 0.39 & 20 & 75.9 \\
\hline Posterior longitudinal ligament & 12.5 & 0.39 & 10 & 51.8 \\
\hline Ligamentum flavum & 2.4 & 0.39 & 6 & 78.7 \\
\hline Interspinous ligament & 3.4 & 0.39 & 6 & 36.3 \\
\hline Supraspinous ligament & 3.4 & 0.39 & 2 & 75.7 \\
\hline Transverse ligament & 3.4 & 0.39 & 10 & 2 \\
\hline
\end{tabular}

\section{Boundary and loading conditions}

The degrees of freedom of inferior surfaces of L5 were completely fixed in all directions, and $10 \mathrm{Nm}$ flexion, $10 \mathrm{Nm}$ extension, $10 \mathrm{Nm}$ lateral bending, and $10 \mathrm{Nm}$ axial rotation moment under $800 \mathrm{~N}$ compressive loading were imposed on the $\mathrm{L} 3$ superior endplate of all models respectively. The maximum load was achieved in five load steps in each model and the main parameters including intradiscal pressure, intersegmental rotation and maximum tresca stress of annulus fibrosus at the L3-4 segment were investigated.

\section{RESULTS}

The results of the three parameters of intradiscal pressure, intersegmental rotation and tresca stress at the L3-4 segment are represented in Figure 2, 3 and 4. In ALIF and normal models, the values of the three parameters on left lateral bending and axial rotation were equal to those on right lateral bending and axial rotation. While in the TILF model, the values on right

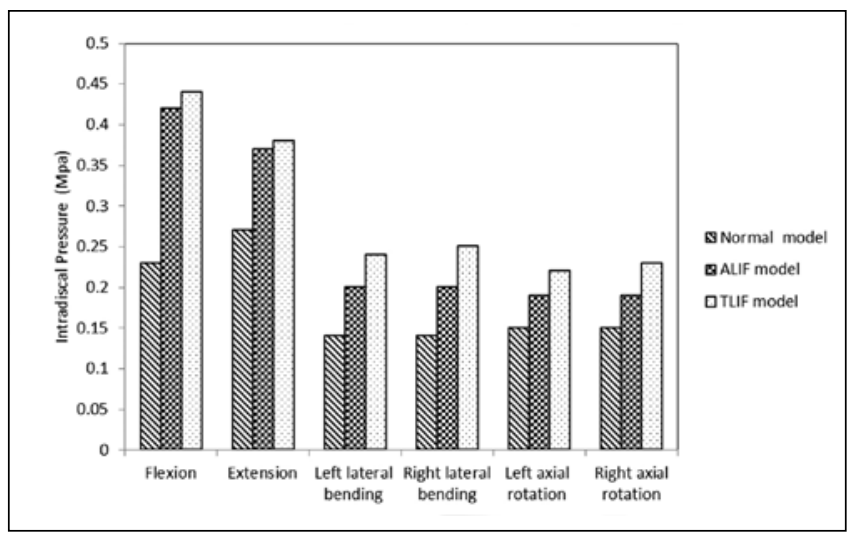

Figure 2: Intradiscal pressure in different loading directions and models. lateral bending and axial rotation were larger than those on left lateral bending and axial rotation.

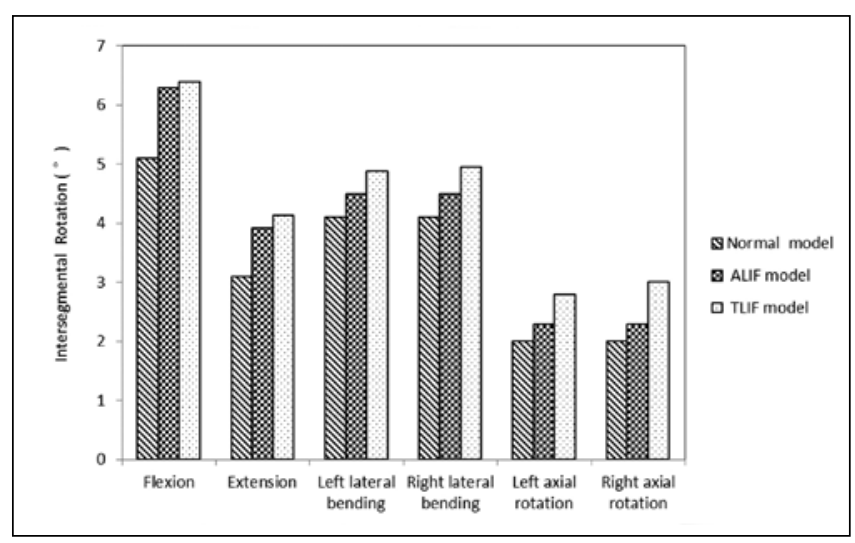

Figure 3: Intersegmental rotations in different loading directions and models.

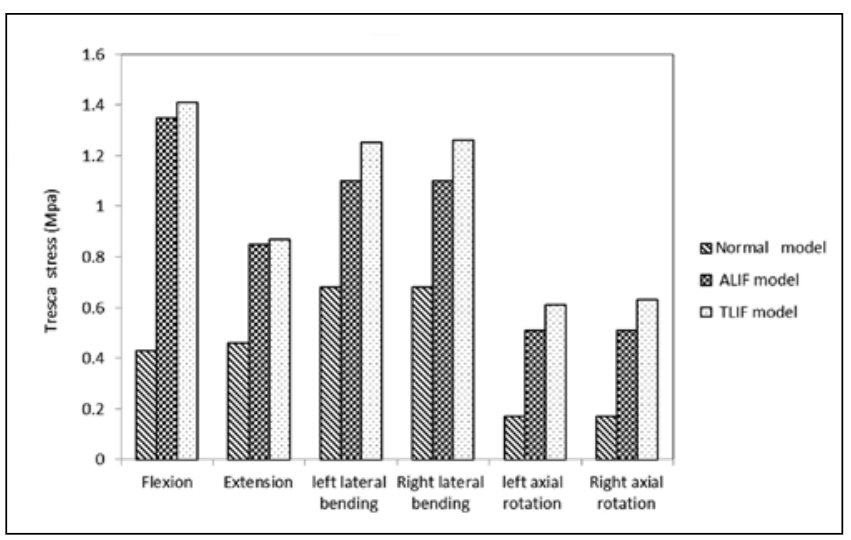

Figure 4: Tresca stress on annulus fibrosus in different loading directions and models. 
The intradiscal pressure of L3-4 in different loading directions and models are displayed in Figure 2. Under all loading directions, the intradiscal pressure in the TLIF model is the highest and presented with 0.44Mpa, 0.38Mpa, 0.24Mpa, $0.25 \mathrm{Mpa}, 0.22 \mathrm{Mpa}$ and $0.23 \mathrm{Mpa}$ on flexion, extension, left lateral bending, right lateral bending, left axial rotation and right axial rotation respectively. The intradiscal pressure in the normal model is the lowest and presented with $0.23 \mathrm{Mpa}$, $0.27 \mathrm{Mpa}, 0.14 \mathrm{Mpa}$ and $0.15 \mathrm{Mpa}$ on flexion, extension, leftright lateral bending and left-right axial rotation. In all loading directions, the intradiscal pressures in ALIF model were higher than normal model, while lower than the TLIF model.

The intersegmental rotations of L3-4 in different models and loading directions are displayed in Figure 3. Under all loading directions, the intersegmental rotation of the TLIF model is the largest with $6.4^{\circ}$ on flexion, $4.1^{\circ}$ on extension, $4.8^{\circ}$ on left lateral bending, $4.9^{\circ}$ on right lateral bending, $2.8^{\circ}$ on left axial rotation and $3.0^{\circ}$ on right axial rotation, and the values in the normal model are the lowest with $5.1^{\circ}$ on flexion, $3.1^{\circ}$ on extension, $4.1^{\circ}$ on left-right lateral bending and $2^{\circ}$ on leftright axial rotation. The ALIF model presented with $6.3^{\circ}$ on flexion, $3.9^{\circ}$ on extension, $4.5^{\circ}$ on left-right lateral bending and $2.3^{\circ}$ on left-right axial rotation, which are larger than the normal model, but lower than the TLIF model.

The tresca stresses on the L3-4 annulus fibrosus in different models and loading directions are displayed in Figure 4. These are higher in the TLIF model than in any of the other models in all loading planes with 1.41MPa on flexion, $0.87 \mathrm{MPa}$ on extension, 1.25MPa on left lateral bending, 1.26MPa on right lateral bending, $0.61 \mathrm{MPa}$ on left axial rotation and $0.63 \mathrm{MPa}$ on right axial rotation. The normal model has the lowest values of tresca stress with $0.43 \mathrm{MPa}$ on flexion, $0.46 \mathrm{MPa}$ on extension, $0.68 \mathrm{MPa}$ on left-right lateral bending, and $0.17 \mathrm{MPa}$ on left-right axial rotation. Similar to intradiscal pressure and intersegmental rotation, the tresca stresses in the ALIF model are larger than the normal model, but lower than the TLIF model in all loading directions.

\section{DISCUSSION}

In the present study, we analyzed and compared the biomechanical influence of TLIF and ALIF on the superior adjacent intervertebral disc using finite element techniques, and we attempted to determine if TLIF aggravates adjacent segment degeneration more adversely than ALIF by comparing the parameters of intradiscal pressure, intersegmental rotation and tresca stress in L3-4.

Adjacent segment degeneration is a well-recognized and frequent long-term consequence of lumbar interbody fusion. Lumbar fusion may lead to decreased elasticity and increased stiffness, resulting in stress concentration at the adjacent segments. This may adversely affect the adjacent disc and aggravate its degeneration. Many studies have reported the effect of lumbar fusion on the adjacent segments. These findings are confirmed through in vitro experiments by Rao (7), Weinhoffer (11), Chen (1) and Chow (2) all suggesting that hypermobility, tresca stress and intradiscal pressures are increased within adjacent segments. In the present study, we found at the adjacent superior segments in flexion, extension, axial rotation and lateral bending, the values of the range of motion, the intradiscal pressure and tresca stress at L3-4 segment are significantly larger in ALIF and TLIF models than normal spine model, which is consistent with the aforementioned studies, demonstrating that both ALIF and TLIF can promote adjacent segmental degeneration.

The lumbar function unit, with interdependent components distributing loads and guiding movements, involves the intervertebral disc, the posterior facet joints and ligamentous system. The facet joints and posterior ligamentous system play an important role in loading distribution in addition to the intervertebral disc. The anatomical orientation of the lumbar facet joints indicates that their major function is the control and stabilisation of torsional forces, leading to some limitations on the motion of lumbar function units, especially on lateral bending and axial rotation, which may affect the intersegmental rotation and stress distribution, and subsequently affect the biomechanical characteristics of adjacent segments. The posterior ligamentous system also influences stress distribution, and Ekman (3) found a significantly higher incidence of ASD in patients with laminectomy compared to non-laminectomised patients in a prospective randomised study of 111 patients on the longterm effect of lumbar fusion on adjacent disc degeneration, suggesting laminectomy may be of pathogenetic importance for ASD development. It could be that the loss of posterior tension band function creates instability and, hence, accelerates disc degeneration (3). In the present study, we created the TLIF model according to the standard technique of TLIF surgery, in which the left facet joint was completely removed and left superior and inferior lamina were partially removed, and as a result, the biomechanical situation of the adjacent segment would be affected. Theoretically, the left facet joint removal may have more influence on the adjacent segment on lateral bending and axial rotation than on flexion or extension. In the present study, we found the intradiscal pressure, intersegmental rotation and tresca stress of TLIF model to be higher on right lateral bending and right axial rotation than left lateral bending and left axial rotation, indicating the effect of facetectomy and laminectomy on the loading conduction. There was just a minor difference between the left and right side, maybe because the effect of facetectomy and laminectomy was offset by the solid fusion obtained by interbody fusion and intertransverse fusion.

In addition, when compared to the ALIF model, the values of the intradiscal pressure, intersegmental rotation and tresca stress in the TLIF model on lateral bending and axial rotation were larger than those in ALIF, and our results demonstrate that the intradiscal pressure of the L3-4 segment increases $20 \%, 25 \%, 15.8 \%$ and $21.1 \%$, the intersegmental rotation increases $8.4 \%, 10 \%, 21.7 \%$ and $30.9 \%$, and the tresca stress increases $13.6 \%, 14.5 \%, 19.6 \%$ and $23.5 \%$ on left lateral bending, right lateral bending, left axial rotation and right 
axial rotation respectively from the ALIF to the TLIF model. However, under flexion and extension directions, the values of the three parameters show a small increase, and the intradiscal pressure in the TLIF model increases $4.8 \%$ and $2.7 \%$, the intersegmental rotation increases $1.6 \%$ and $5.4 \%$, and the tresca stress increase $4.4 \%$ and $2.4 \%$ on flexion and extension respectively, compared with the ALIF model. We therefore suggest that the intertransverse fusion may have more influence on the loading conduction on lateral bending and axial rotation, while a relatively small influence on flexion and extension. Although the main plane of motion in the lumbar spine is in flexion and extension, we can find a clear trend that TLIF leads to higher intradiscal pressure, intersegmental rotation and tresca stress at L3-4 segment when compared to ALIF model, and we therefore conclude that TLIF influences adjacent segmental degeneration more adversely than ALIF.

However, our study does have inherent limitations. To facilitate the study, the structure of the vertebral body was assumed to be isotropic and homogenous and the bone graft was assumed to completely occupy the disc space and intertransverse space, and all the fusion was assumed to be solid fusion, which may not be truly representative of the in vitro or clinical situation. In addition, the present finite element model does not account for the mechanical effect of muscle contraction and the loading conditions were not truly physiological. More studies are needed to further clarify these effects.

\section{REFERENCES}

1. Chen CS, Cheng CK, Liu CL, Lo WH: Stress analysis of the disC adjacent to interbody fusion in lumbar spine. Med Eng Phys 23:483-491, 2001

2. Chow DH, Luk KD, Evans JH, Leong JC: Effects of short anterior lumbar interbody fusion on biomechanics of neighboring unfused segments. Spine (Phila Pa 1976) 21:549-555, 1996
3. Ekman $\mathrm{P}$, Moller $\mathrm{H}$, Shalabi A, Yu YX, Hedlund R: A prospective randomised study on the long-term effect of lumbar fusion on adjacent disc degeneration. Eur Spine J 18:1175-1186, 2009

4. Fantigrossi A, Galbusera F, Raimondi MT, Sassi M, Fornari M: Biomechanical analysis of cages for posterior lumbar interbody fusion. Med Eng Phys 29:101-109, 2007

5. Hsieh PC, Koski TR, O'Shaughnessy BA, Sugrue P, Salehi S, Ondra S, Liu JC: Anterior lumbar interbody fusion in comparison with transforaminal lumbar interbody fusion: Implications for the restoration of foraminal height, local disc angle, lumbar lordosis, and sagittal balance. J Neurosurg Spine 7:379-386, 2007

6. Niemeyer T, Halm H, Hackenberg L, Liljenqvist $U$, Bovingloh AS: Post-discectomy syndrome treated with lumbar interbody fusion. Int Orthop 30:163-166, 2006

7. Rao RD, David KS, Wang M:Biomechanical changes at adjacent segments following anterior lumbar interbody fusion using tapered cages. Spine (Phila Pa 1976) 30:2772-2776, 2005

8. Schmidt H, Heuer F, Simon U, Kettler A, Rohlmann A, Claes $\mathrm{L}$, Wilke HJ: Application of a new calibration method for a three-dimensional finite element model of a human lumbar annulus fibrosus. Clin Biomech (Bristol, Avon) 21:337-344, 2006

9. Tang S, Meng X: Does disc space height of fused segment affect adjacent degeneration in ALIF? A finite element study. Turk Neurosurg 21:296-303, 2011

10. Tang S, Rebholz BJ: Does anterior lumbar interbody fusion promote adjacent degeneration in degenerative disc disease? A finite element study. J Orthop Sci 16:221-228, 2011

11. Weinhoffer SL, Guyer RD, Herbert M, Griffith SL: Intradiscal pressure measurements above an instrumented fusion. A cadaveric study. Spine (Phila Pa 1976) 20:526-531, 1995

12. White III AA PM: Clinical Biomechanics of the Spine. In White III AA, Panjabi MM (eds), Clinical Biomechanics of the Spine. Philadelphia: J B Lippincott Company 1990 